\title{
Lockdown, employment adjustment, and financial frictions
}

\author{
Povilas Lastauskas (iD
}

Accepted: 13 April 2021 / Published online: 3 June 2021

(C) The Author(s), under exclusive licence to Springer Science+Business Media, LLC, part of Springer Nature 2021

\begin{abstract}
We examine firms' employment adjustments immediately after the imposition of stringent lockdown in March 2020. In doing so, we use monthly administrative data, and take value-added tax payment changes as a proxy for the demand shock. We merge data with COVID-19 tests, classified by economic activity, and employ a fixed effects instrumental variable regression. We find that all sized firms in the manufacturing sector reduced employment more if they had uncovered tax liabilities before the lockdown. Among small firms, real estate and service sector firms downsized more rapidly. While employment changes are rather modest, this very early evidence points to the need to address liquidity needs and firm pre-conditions among capital-intensive and services firms and, in particular, small businesses, to avoid employment losses.
\end{abstract}

Plain English Summary The administrative data from the first COVID-19 lockdown in 2020 point to the need to address liquidity requirements among manufacturers, capital-intensive and service firms, and, in particular, small businesses to avoid subsequent employment losses.

While there is a vast literature on firms' adaptation and adjustments in the face of adverse shocks,

P. Lastauskas $(\bowtie)$

Center for Excellence in Finance and Economic Research and Faculty of Economics and Business

Administration, Bank of Lithuania and Vilnius University, Vilnius, Lithuania

e-mail: Povilas.Lastauskas@ef.vu.lt firms' reactions and the macroeconomic implications of stringent, government-imposed lockdowns are much less understood due to their novelty. We analyze businesses' responses to the first and very stringent lockdown in March 2020 by making use of monthly administrative data and taking value-added tax payment changes as a proxy for the demand shock. We exploit variation in the sectoral differences across small, medium, and large firms. A simple average employment adjustment was non-negative in agriculture, construction, information and communication, and public administration sectors in our sample. By merging data with COVID-19 tests, classified by economic activity, and employing a fixed-effects instrumental variable regression, we find that all sized firms in the manufacturing sector reduced employment more if they had uncovered tax liabilities before the lockdown. Among small firms, real estate and service sector firms downsized more rapidly. While employment changes are rather modest, this very early evidence about businesses' reactions to COVID-19induced uncertainty and activity restrictions points to the need to address business liquidity needs early on. Another policy message concerns the importance of firm pre-conditions among capital-intensive and services firms and, in particular, small businesses to avoid subsequent employment losses.

Keywords Matched data - Employment · Firm size · Sectoral heterogeneity · Lockdown · Financial frictions 
JEL Classifications C30 - C55 - D22 - L26 - M51

\section{Introduction}

While there is a vast literature on firms' adaptation and adjustments in the face of adverse shocks, firms' reactions and the macroeconomic implications of stringent, government-imposed lockdowns are much less understood due to their novelty. We use administrative data, which provides us with timely evidence on businesses' immediate reactions to the government's announced first national quarantine, aimed at stopping the spread of COVID-19 and gaining time to learn about the virus. Unlike early evidence, based on stated responses in firm surveys, we use revealed actions at the outset of lockdown, registered at a monthly frequency, and covering all registered VAT-paying firms in Lithuania, a small and very open European Union economy. The lockdown announced on 14 March 2020 entailed the closure of borders and schools, the cancellation of public events, and the shutdown of all non-essential shops, museums, cinemas, and similar establishments. ${ }^{1}$ Such a drastic measure, imposed earlier than in many other countries in Europe with a substantially larger number of virus cases, provides us with an opportunity to consider a shock as a natural experiment and thus zoom in on firms' reactions.

To causally identify firm employment adjustments, we make use of the unequal exposure to the lockdown: while some sectors were better prepared (such as IT, banking, and other sectors with flexible employment practices), others lacked required arrangements or could not move their activities online (such as the service sector, accommodations, and hospitality), ${ }^{2}$

\footnotetext{
${ }^{1}$ The government's decision came as a big surprise. The country registered its first COVID-19 case on 28 February 2020 and had only nine confirmed cases, according to the Health Ministry's official announcement on 15 March 2020. Nonetheless, the government had forward-guided about the strict nationwide lockdown on 14 March 2020 to commence on 16 March. Note that the registered number of cases refers to 13 March data, the delay in announcement reflecting the time needed to carry out tests (see details on the health ministry website).

${ }^{2}$ The importance of the sectoral aspect lies not only in the specifics of the current shock, requiring social distancing, and thus favoring remote work and more cognitive skills but also in inherent differences in types of labor across sectors. According to Hall and Lazear (1984), excessive layoffs in bad times stem from the specific nature of worker-firm relations, giving rise to a bilateral monopoly. Clearly, different types of workers
}

and, therefore, were more adversely affected. The heterogeneity of the shock is also evident in the datadespite government recommendations to stay at home even for work purposes, some activities were nevertheless carried out, from manufacturing to the health sector. Some activities, such as online retail shopping and IT use, have received a substantial boost. Given the precipitous and drastic lockdown impositionwhen anticipation was not feasible and economic policies to help businesses had not yet been set out-we look at how firm employment has changed, exploiting value-added tax payments to the State Tax Agency as a proxy for the magnitude of a shock. The study no only contributes to gathering policy implications, drawing lessons for future interventions, but also sheds fresh light on the sources of heterogeneity of firm resilience and adjustment margins.

We delve into the sectoral differences across small, medium, and large firms. A simple average employment adjustment was non-negative in agriculture, construction, information and communication (ICT), and public administration sectors in our sample. The first item makes perfect sense due to demand and seasonality reasons. Construction works could have been carried out outdoors (thereby reducing a contagion risk), and the new idle workforce could have been used to speed up current projects. ICT was crucial for workplace transformation, and, finally, public sector jobs tend to be relatively secure and thus act as a shield in times of uncertainty. Other sectors, by contrast, experienced employment reductions. Therefore, the lack of targeted policies has caused specific industries suffer more than others.

Given the context and data availability, we contribute to the literature by answering three inter-related questions. First, we quantify the effect of immediate changes in sales taxes (proxying for a shift in demand) as a response to the first national COVID19-induced lockdown on employment changes. We exploit specifications controlling for the firm, section, or sector effects. Our focus is on the extensive employment margin, which is the only one that we observe.

are concentrated across various sectors. When bargaining power rests with the employer, the adjustment occurs by first firing the least protective type of labor (e.g., short-time work helps reduce cyclicality in other types of employment in the face of a negative demand shock, Lydon et al. 2019). Though we do not observe types of labor or their composition differences, we allow for sectoral heterogeneity to drive responses to the shock. 
Arguably, this margin is the most relevant one due to relative wage rigidity (even though the Lithuanian labor market is more flexible than its Western Europe counterparts, rewriting contracts does require time and also accrues firing costs for the employer if an employee refuses to the accept new terms), ${ }^{3}$ and a very short time frame to capture the most immediate firm responses. ${ }^{4}$ Second, we explore the role of pre-existing financial frictions, paying particular attention to sectoral heterogeneity (which is critical due to differences in how different sectors respond to the shock). Third, we shed more light on the role of firm size and employment adjustment, exploiting COVID-19 tests at the sector level as a continuous measure of exposure.

We also contribute to the emerging literature trying to categorize sectors by the nature of the shock (supply or demand) and sectoral as well as macroeconomic effects, e.g., Baqaee and Farhi (2020), Bekaert et al. (2020), del et al. (2020). In addition, we portray another angle, where not only sectoral differences are taken into account but also existing financial frictions at the firm level are interacted with the shock. Although finding the largest adjustment among small firms with no significant effect among the largest companies may not be surprising, the causes for differences across sectors are less understood. More precisely, pre-shock financial frictions are found to be employment-reducing within the most capital-intensive sectors, namely agriculture, manufacturing, construction, and real estate. For instance, using a flexible instrumental variable regression and controlling for firm fixed effects, we find that a small manufacturing firm reduces employment by more if it carries a financial obligation from 2019, whereas larger manufacturing firms are relatively better at protecting their labor force. Therefore, the effects of financial frictions depend on the nature of the sector

\footnotetext{
${ }^{3}$ According to the current Labor Code, an employer covers a severance pay equal to two monthly salaries. Moreover, an employee who worked more than 5 years at the company is granted the right to claim a long-term unemployment benefit after three months of unsuccessful job search.

${ }^{4}$ After history unfolds, of course, intensive and extensive margins will shed more light on the response dynamics. As shown by Kwapil (2009), using survey data, a decline in sales causes firms to reduce wages (an intensive margin). Wage cuts are accepted if the company's existence is at stake. Furthermore, institutions that contribute to wage rigidities play an essential role.
}

(e.g., capital intensity) and the firm's size within a sector. Importantly, these findings indicate the dominance of supply-driven forces, using taxonomy used by Baqaee and Farhi (2020) at the outset of the lockdown. Ex-post, this also helps to explain why upon lifting lockdown restrictions the economy has bounced back so quickly.

The paper is structured as follows. We proceed with a discussion of macroeconomic trends and small and medium enterprises (SMEs), along with insights from the literature, in Section 2. A description of the context and data facts are given in Section 3. We cover baseline results in Section 4. We control for firm, sector, and section effects, but do not allow for state variables or response heterogeneity. In Section 5, we extend the analysis and cover pre-shock firm-level conditions, including turnover, labor costs, and financial frictions (tax wedges), and different responses due to firm sizes. To robustify our findings, Section 6 reports results from the instrumental variable fixed effect regression model, where we control for firm heterogeneity and address the potential endogeneity of the firm payments variable. Finally, we conclude by summarizing, outlining future work and a few policy implications in Section 7.

\section{Macroeconomic trends and SMEs}

\subsection{Macroeconomic performance}

Before analyzing data, we take stock of the macroeconomic context, sectoral trends, and business performance. We start with documenting price changes in a few categories of the consumer price index, similarly to the dis-aggregated Keynesian model with supply and demand constraints by Baqaee and Farhi (2020). The idea is that supply shocks affect consumers' choices by affecting prices and incomes, whereas demand shocks impact consumers' choices for fixed prices and income. According to Baqaee and Farhi (2020), their model-implied classification predicts health and transportation to be demand-driven, but food, beverages, and construction, among others, to be supply-constrained.

We document monthly price changes in Fig. 1 which agrees with the proposed classification. An increase in demand for health services resulted in slight price rises, whereas a drop in transportation demand ended up with a huge price adjustment 
Fig. 1 The harmonized monthly consumer price index across selected categories before and during the lockdown (base year: 2015). (Data source: Statistics Lithuania; own calculation and representation)

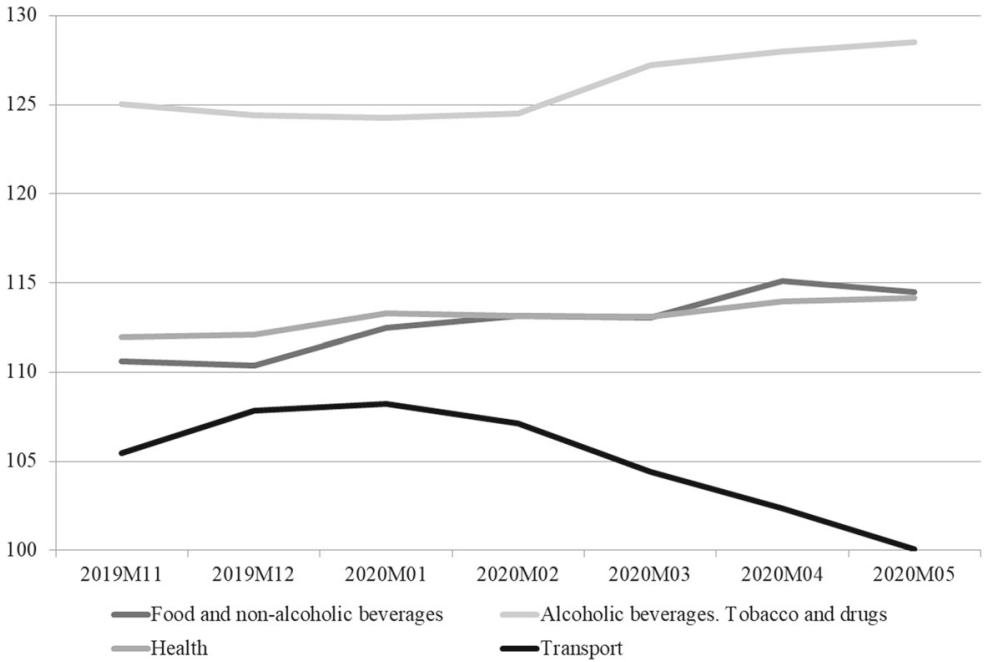

downwards. A reduction in supply delivered price increases in food, and especially alcoholic beverages and tobacco. The mix of supply and demand changes plays an important role in macroeconomic performance, transmission of shocks within the sectoral network, and policy lessons. However, the Lithuanian economy has mainly suffered from supply-side constraints, to be further corroborated by firm-level data.

Having seen that the lockdown period is associated with substantial price adjustments, not usually registered for the same time interval over other periods, we move from domestic to openness dynamics. As can be inferred from Fig. 2, the lockdown's magnitude is immense for the hospitality sector (right axis). Despite a staggering drop in hotel occupancy rate, the overall exposure was minimal (which is why the domestic economy was more resilient) due to the small tourism sector (it is about $2.2 \%$ of GDP). This means that, unlike more tourism-oriented economies, the shock has been largely contained within a small sector.

More importantly, however, Lithuania is a very open economy (its exports plus imports ratio over GDP, openness ratio, is around $150 \%$, see Lastauskas and Stakenas, 2018), and trade could be a more severe threat to spill a negative shock across domestically oriented sectors. The export value has indeed shrunk considerably; however, there was a quick rebound. Importantly, Lithuania managed to put forward higher
Fig. 2 Dynamics of monthly export value (in thousand Euro, left axis) and monthly hotel occupancy rate (right axis) before and during the lockdown. (Data source: Statistics Lithuania; own calculation and representation)

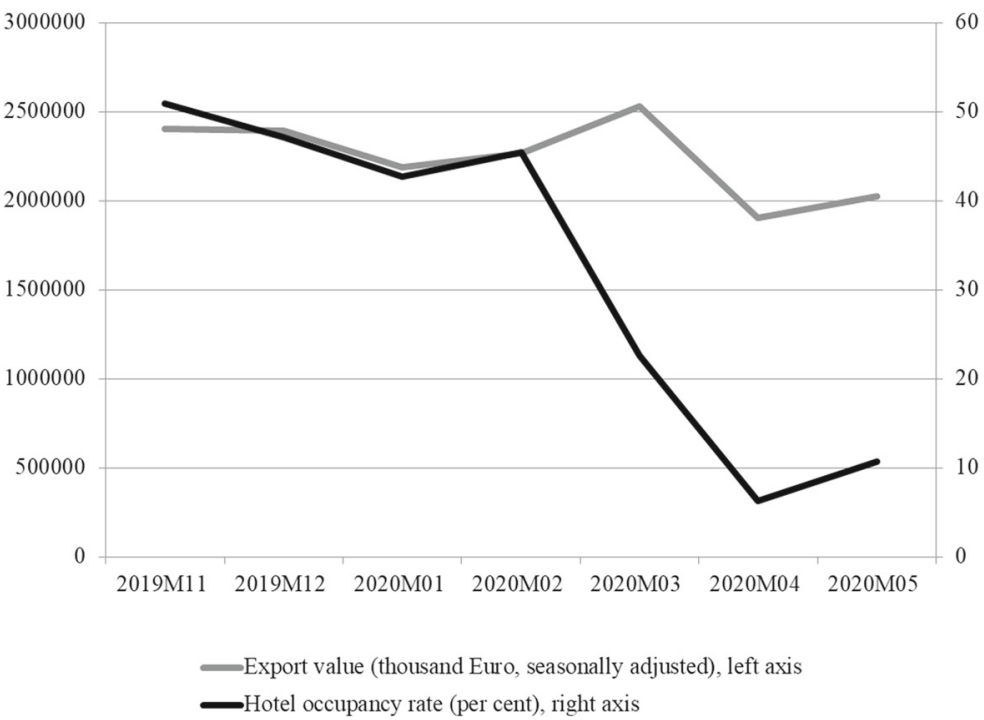


added-value goods essential for research and control of the virus, which helped to balance out the considerable drop in exports of mineral products, intermediate consumption, and consumer goods. Moreover, the country's imports of goods and services decreased more than exports, which in turn led to a rise in net exports that made a positive contribution to Lithuania's real GDP growth. Hence, the impact of the first lockdown in March 2020 has been mainly limited to domestic adjustments.

\subsection{SMEs in the face of crisis}

Having observed substantial adjustments within sectors, though mainly concentrated in supplyconstrained activities, we take stock of the literature about firm adjustments in the face of a negative shock. While we only look at the immediate impact of the lockdown, which came as a shock and is free from economic policy interventions, on employment, many associated events might get triggered. A useful direction in this respect was proposed by Huynh et al. (2017), who make use of a Canadian firm-worker matched employment database to explore the impact of industry shutdown rates on workers at the continuing firm. They find that a firm's shutdown within an industry decreases earnings growth and even makes the probability of permanent layoffs more likely at continuing firms. In other words, containing closures can have large positive spillovers. As documented above, the initial response was limited and did not translate into substantial demand constraints, whereas to gauge the full effects of sectoral transmission and full reallocation would require more time and a longer horizon. However, our early look into sector and section level adjustments helps to elucidate sectoral heterogeneity in response to the health crisis's early stages. As demonstrated by Domenech (2008), one of the reasons why particular sectors engage in larger adjustments concerns sector cyclicality, unionization, and local collective bargaining institutions. What makes the COVID-19 induced crisis special is the unequal sectoral exposure to the disrupted global value chains as well as different preparedness to adjust workplace conditions to mitigate workers' contagion risk while at work. A similar point, regarding sectoral heterogeneity in terms of demand and supply constraints, has also been stressed by Baqaee and Farhi
(2020). The authors advocate for a targeted demand stimulus, which is more effective and does not translate into price increases for those sectors which are supply, not demand, constrained.

The aspect of targeted policies, which take into account pre-conditions and sectoral heterogeneities, is a recurring topic in the vast literature. After the global financial crisis, the financial conditions before a crisis were shown to play a determining role in explaining firms' adjustments (see, among many others, recent contributions due to Boeri et al., 2018, Berton et al., 2018, and references therein). We explore if this time is indeed so different from historical crises (Reinhart, 2020), and, as in past disasters, the responses had no connection to financial pre-conditions. Our conclusions are more nuanced: only particular sectors suffered from inherited uncovered liabilities and thereby engaged in downsizing. We find that firm size plays an important role. In a calibrated search and matching model with endogenous job destruction, Elsby and Michaels (2013) analyze the role of firm size and document a substantial cyclicality in job creation. They also predict that the share of small establishments with fewer than 20 workers rises during recessions, whereas the shares of larger firms decline. Though we do not observe firm entries and exits, we document important differences in adjustment dynamics, depending on the firm size, even controlling for a rich set of variables. Lastly, we conduct instrumental variable estimations to control for any strategic response or self-selection effects. We find that pre-shock leverage matters, particularly for capital-intensive and service sectors.

From a more macroeconomic perspective, Auray and Eyquem (2020) look at the effects of lockdown on unemployment. They find that that unemployment doubles on impact, precautionary savings go up due to a surge in unemployment risk, and a drop in demand outpaces that of supply, leading to a deflationary trend. The authors predict substantially grimmer macroeconomic effects than have thus far been observed in reality (due to sluggishness in European labor markets, the effects of the shock, they predict, will last at least until 2025). A more optimistic scenario has been suggested by Mihailov (2020) who uses the Gali et al. (2012) model, predicting a loss of per-capita consumption of around 6-7\% (from the long-run trend) and per-capita output (3-4\% down) with a relatively 
quick (1-2 years) recovery in the most optimistic scenario of a one-quarter lockdown wherein one-fourth of the labor force is unable to work. Even such a scenario is bleak for Lithuania's case; our firm-level data show a modest employment adjustment in the face of the first lockdown, with economically meaningful results only for the most extremely affected companies, and only if the lockdown lasts for substantial periods. It seems that supply-constrained sectors have not created significant demand shocks, and the core sectors remained robust.

Substantial uncertainty surrounds not only virus containment but also policy interventions, which happened to be unprecedented, thus possibly changing trajectories of economic response. One of our analysis's advantages, exploiting the early effects of the lockdown and real-time data, is the clean identification of firm adjustments, unaffected by policy interventions. In fact, when the lockdown was enforced, there were neither fully worked out furlough schemes in Lithuania (they were approved in April 2020 by the Parliament) nor a clear idea of state aid (although there was a simultaneous announcement of unprecedented forthcoming plans). Ex post, only a portion of the announced policies have been implemented. As we will see, although most companies made no immediate employment adjustments, more companies opted for employment reduction than expansion, despite the government's guidance on imminent assistance.

\section{Data facts}

For the analysis, as already mentioned, we track registered VAT-paying firms. There are 74,372 companies over the entire 2019 year and the first 4 months of 2020. Since the data are generated at the end of April 2020 , some firms may not have reported their payments; we thus analyze those firms that have entries for both months (March and April, 2020). We will use a change in firm-level variables to infer the immediate effects of the lockdown. There are 52,813 companies with tax payment entries for March and 36,045 companies for April, ranging from 1 employee to 14,207 employees in March (14,010 in April). There were 8325 non-zero changes in employment for those companies that reported VAT payments, out of which 4422 resulted in employment reduction. Even though more companies reduced rather than increased employment, the fraction of expanding firms exceeded the $46 \%$ of those that adjusted employment. Figure 3 plots kernel densities for changes in employment and VAT tax payments, conditional on non-zero adjustments. Both changes are left-skewed, with substantially larger drops in tax payments, as expected, given a dramatic reduction in economic activity.

Some companies had covered VAT accounts above their liabilities, ${ }^{5}$ whereas some were indebted to their employees. We will make use of these pre-conditions when analyzing responses to the COVID-19-induced shock. Summary statistics for the variables are provided in Table 1. The Tax and Social Insurance Agencies' matched data provide us with early evidence about revealed, not stated, actions. In fact, our data is unique as it merges information, at the firm level, on employment, salaries, turnover, VAT payments, and obligations for the State Tax Agency, along with sector and section information. We will refer to the economic classification as a sector and its richer classification as a section. Altogether, we cover 19 sectors, which can be further divided into 83 sections. This classification allows us to conduct an instrumental variable regression, since COVID-19 tests have also been registered by the economic activity classifier. This enables us to match positive test data with the firm-level dataset, allocating the same entry to all firms from the same economic activity group.

\section{Baseline results}

Our empirical strategy is to exploit changes in positive tax payments to the State Tax Agency. The idea is that a large drop in VAT payments indicates the size of the shock, capturing reduced economic activity. We focus on those active firms whose tax rebates do not exceed factually paid taxes. In fact, positive payments exceed $96 \%$ of cases for both March and April 2020. We take natural logarithms to focus on growth rates of employment and VAT tax payments. This is to account for scale differences and attenuate the effects of extreme values (it also makes the intuitive interpretation of results in terms of percentage points). The

\footnotetext{
${ }^{5}$ Correct to date, a company does not receive an overpayment of VAT taxes from the State Tax Agency immediately but in specific amounts and after certain conditions are satisfied. It is anticipated that immediate clearing will be done for reliable taxpayers as an incentive mechanism from 2021 onwards.
} 
Fig. 3 Epanechnikov kernel densities of changes in employment and VAT tax payments (log scale)

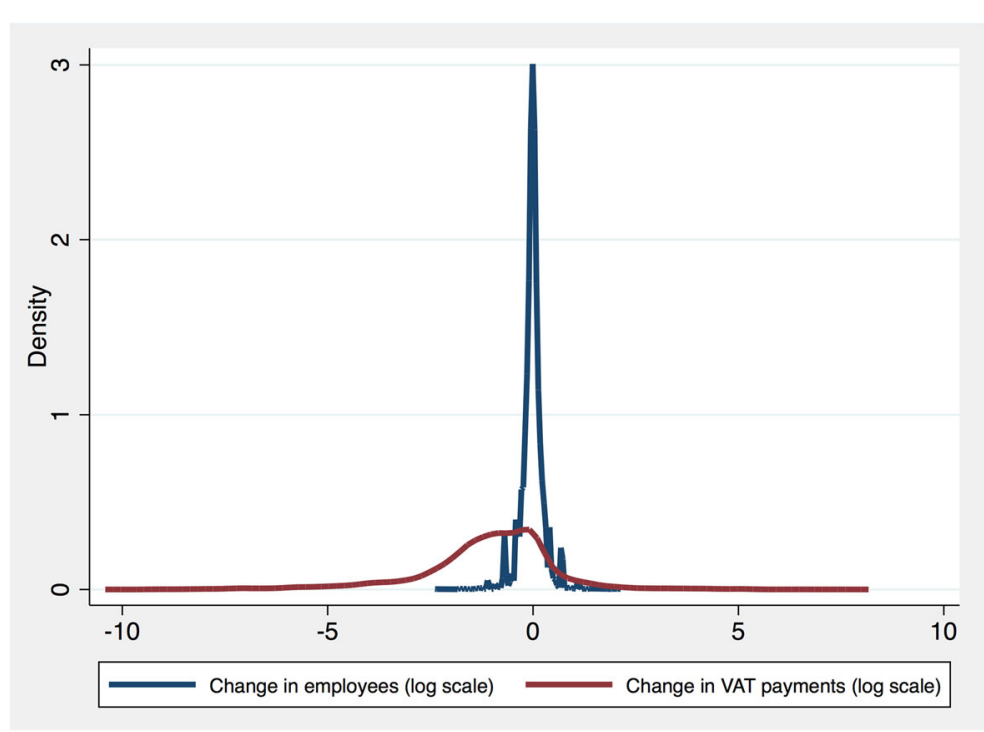

first piece of visual evidence is summarized in Fig. 4. Pooling across all firms from all industries, there is a clear positive relationship between tax payments and employment growth, both when payments grow and when they decline. More precisely, a large positive change in VAT (sales) taxes is associated with an increase in employment, whereas a negative change is linked to employment reduction.

Most importantly, however, given an unprecedented shock - the March 2020 lockdown — a monthly change can be thought of as a "natural experiment" wherein an unprecedented shift in economic activity has resulted (there were no other events of comparable scale at a monthly frequency). The shift could have been negative (e.g., service firms) or positive (e.g., technology sector). The local polynomial curve with the associated $95 \%$ confidence interval demonstrate that the "left tail" is the main driver of the conditional relationship (conditionality refers to a non-zero (either positive or negative) change in employment before the lockdown and during its first phase): ${ }^{6}$ when tax payments drop to almost zero, which captures the intensity of the economic activity drop, thereby leading to immediate employment adjustment. Given that employment is a costly adjustment margin due to firing and hiring costs, search costs, job- and match-

\footnotetext{
${ }^{6}$ The lockdown officially ended on 16 June 2020 (but the state of emergency state has continued, thereby enabling companies to receive subsidies from the government), though its easing had already started in April 2020.
}

specific capital, and many other reasons, it has to be that the intertemporal savings of keeping a job are lower than the benefit. Some firms have to face not only a large immediate drop in demand and/or constraint in supply but also see particularly poor prospects that make them opt for cost-cutting via an extensive margin of employment.

\subsection{Tax payments and employment level}

Even though the visual evidence is only conditioned on a non-zero change in employment, firms differ across sectors, by sizes, financial conditions before the lockdown, and other features. Thus, we start with a simple before-and-after regression, which holds all factors across sectors or sections fixed:

$y_{i j t}=\alpha_{\{i, j\}}+\beta \triangle \ln$ Tax Payments Pajt $_{i j t}$,

where $y_{i j t}$ can be either a level or a growth rate, i.e., ln Employment ${ }_{i j t}$ or $\triangle \ln$ Employment $_{i j t}, i$ denotes a firm that belongs to the $j$ sector or section (this will be made clear in each table), and $t$ denotes a month (March and April 2020). The fixed effect $\alpha_{\{i, j\}}$ can be either firm-specific, section- or sector-specific. Firms belong to one of 19 sectors, which can be further split into 83 sections. We will also exploit firm fixed effects for employment level (due to matched employment being observed only over March and April, a monthly change delivers one value for employment, thus disabling more granular fixed effects). 
Table 1 Summary statistics

\begin{tabular}{lllll}
\hline Variable & Mean & St. Dev. & Min & Max \\
\hline Employees & 15.06 & 106.49 & 1 & 14010 \\
VAT payments & 5254.46 & $235,625.3$ & $-2.60 \times 10^{7}$ & $2.08 \times 10^{7}$ \\
Annual VAT payments (2019) & $127,419.8$ & 2561361 & $-1.06 \times 10^{8}$ & $3.35 \times 10^{8}$ \\
Annual turnover (2019) & $1,597,799$ & $2.39 \times 10^{7}$ & $-656,187$ & $-779,236$ \\
Annual labor costs (2019) & $213,592.3$ & $1,572,766$ & $-2.58 \times 10^{8}$ & $1.53 \times 10^{8}$ \\
Tax wedge (liability-payments) & $-73,828.48$ & $1,759,407$ & 0 & $5.18 \times 10^{7}$ \\
Negative COVID-19 tests & 165.936 & 486.97 & 0 & 18,464 \\
Positive COVID-19 tests & 3.4846 & 5.742 & 194 \\
\hline
\end{tabular}

Data are combined from Statistics Lithuania and European public policy institute (State Tax Agency), see open source at https://github. com/rzylius/vmi_duomenu_masyvas.

Since the main trigger at such frequency is the pandemic-driven lockdown, we treat the growth rate of tax payments as the "intensity" of the shock. A significant change in layoffs is not trivial. First, we look at the impact results, whereby companies may want to wait and see until the uncertainty is resolved, or at least reduced, since firing and hiring are costly. Second, the government has initiated, and the Parliament has passed, with unprecedented speed, changes in the law which allow furloughed workplaces to be subsidized by the state. ${ }^{7}$. Third, even if the job is redundant, a company could retain a worker on the vocational training scheme, covered by the government. ${ }^{8}$ The last two caveats are limited due to our focus on immediate firm adjustments when economic policies were in the process of preparation.

An observation of abrupt changes in employment is therefore not easy to rationalize and raises ques-

\footnotetext{
${ }^{7}$ The company can choose the magnitude of the subsidy. Still, it cannot exceed either $70 \%$ or $90 \%$ of gross salary (in the former case, it cannot exceed Eur 910.5 or 1.5 minimum wage, whereas in the latter case, it cannot exceed Eur 607 or 1 minimum wage). Employers agree to keep the workplace running for three months after the end date of subsidies. The subsidy scheme is by application only and started on 5 April 2020. According to the State Labor Inspectorate, 17,700 companies declared their employees on furlough; only 2500 applied for subsidies as of 20 April 2020.

${ }^{8}$ Other schemes also include subsidies for the self-employed if they paid taxes before the lockdown for at least three months within the past year, scholarships for students undergoing vocational training even absent studies process, support for grandparents who look after children or extended illness support to look after children when kindergartens and schools are closed, among other policies. See State Labor Inspectorate website.
}

tions about the reasons to start adjustment, given the uncertain length of the lockdown and the anticipation of newly introduced state subsidies. Given high hiring and firing costs, a moderate temporary employment subsidy should be sufficient to avoid layoffs by firms currently operating at losses due to an option value of waiting (Goecke, 2013). Not all interventions are alike, however. For instance, Qi and Schlagenhauf (2018) document that the federal government and the four largest provinces in Canada spend almost half of the corporate income tax revenue. They are not incredibly successful due to dynamic effects, necessitating to raise taxes or cut program spending in the future. However, it is reasonable to think that concerns about future taxes are of secondary importance at the outset of an unprecedented drop in economic activity and forced lockdown, the duration of which was heavily uncertain at the outset.

We start by exploring whether tax payments have any predictive power to explain a change in employment. VAT tax payments are indicative of the magnitude of the shock - either delaying payments or experiencing substantially lower factual payments captures the heterogeneously sized demand shock. As a robustness check, instead of a monthly change before the imposed quarantine and the first month after it, we construct tax payments variables by computing a monthly average in 2019 and compare it to April 2020 (we run a regression with a deviation from the monthly average in 2019 as well as April 2019). The results are not different, thereby reassuring us that we are not capturing seasonality or other data features.

We further proceed with level of employment. Making use of the two time periods, we register an 
Fig. 4 Conditional relationship between a change in VAT tax payments and employment (log scale), given a non-zero employment change

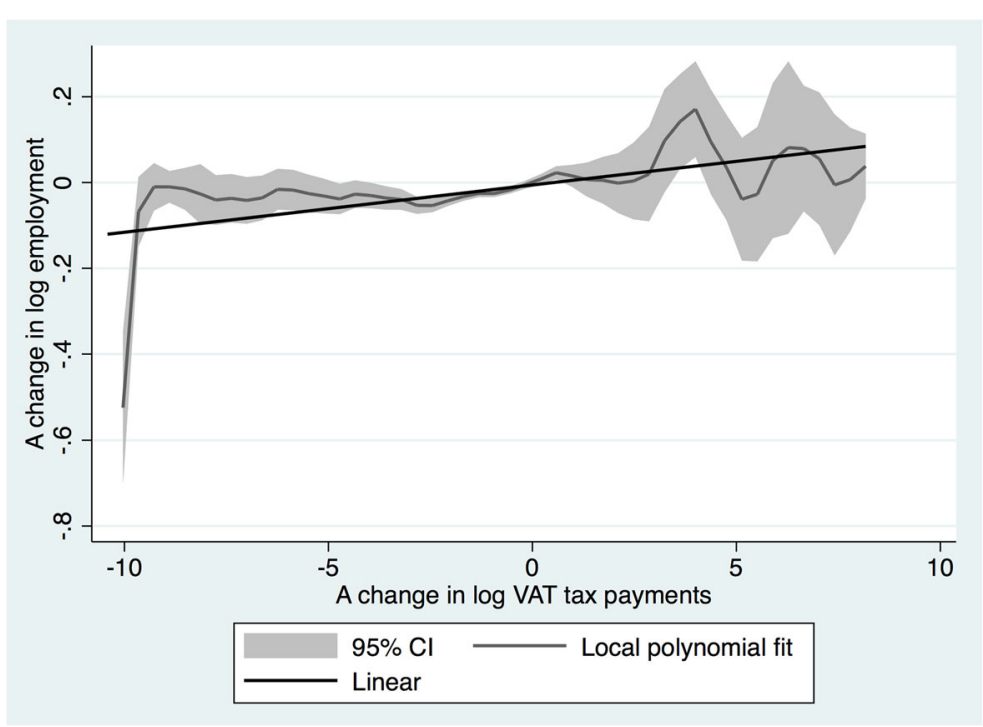

effect of tax payments on firms' employment, controlling for firm fixed effects (see Table 2, Column 1). The results indicate that a $1 \%$ point drop in tax payments leads to a $0.003 \%$ point drop in employment. When we condition on a positive change in employment, the change in tax payments' growth rate turns negative $(-0.034)$, whereas it strengthens and stays positive in the case of employment reduction (0.047). Though the negative sign may seem surprising at first, it makes sense once we dig deeper. After conditioning on the change in tax payments, we find that if both payments and employment increase, then the parameter turns positive and relatively large (0.112). If, however, payments are negative, but employment is positive, then the parameter is negative by construction and equals -0.054 .

Once we do not condition on the payment change, the negative association dominates as there are more firms that employ more people, simultaneously reducing tax payments, than those that increase both employment and VAT tax payments. Since economic activity has dropped for all firms but a few sectors

Table 2 Tax payments and employment: basic regressions

\begin{tabular}{|c|c|c|c|c|c|}
\hline & \multicolumn{3}{|c|}{ Log employment } & \multicolumn{2}{|c|}{$\triangle$ Log employment } \\
\hline & All & $\triangle$ Employment $>0$ & $\triangle$ Employment $<0$ & All & $\triangle$ Employment $\neq 0$ \\
\hline$\triangle$ Log tax payments & & & & $\begin{array}{l}0.0024 * * * \\
(0.0004)\end{array}$ & $\begin{array}{l}0.0091 * * * \\
(0.0012)\end{array}$ \\
\hline Log tax payments & $\begin{array}{l}0.0029 * * * \\
(0.0006)\end{array}$ & $\begin{array}{l}-0.0335 * * * \\
(0.0027)\end{array}$ & $\begin{array}{l}0.0473 * * * \\
(0.0029)\end{array}$ & & \\
\hline Constant & $\begin{array}{l}1.6130 * * * \\
(0.0042)\end{array}$ & $\begin{array}{l}3.0197 * * * \\
(0.0205)\end{array}$ & $\begin{array}{l}2.4242 * * * \\
(0.0219)\end{array}$ & $\begin{array}{l}0.0210 * * * \\
(0.0004)\end{array}$ & $\begin{array}{l}0.0592 * * * \\
(0.0013)\end{array}$ \\
\hline Section fixed effects & No & No & No & Yes & Yes \\
\hline Firms fixed effects & Yes & Yes & Yes & No & No \\
\hline Observations & 84,940 & 8751 & 10,758 & 32,288 & 7,340 \\
\hline$R$-squared & 0.018 & 0.431 & 0.386 & 0.011 & 0.034 \\
\hline
\end{tabular}

Robust standard errors clustered at section level in parentheses

$* * * p<0.01, * * p<0.05, * p<0.1$ 
(e.g., food, agriculture, public sector), future prospects have differed substantially. Among those that shrank their labor force, the absolute majority also reduced VAT tax payments (the parameter is 0.060 once conditioned on a negative monthly change in tax payments). The situation wherein companies increase payments but reduce labor due to a possibly bleak future, by construction, yields a negative association (the parameter is -0.101). Still, the positive effect dominates, as would be suggested by intuition.

\subsection{Tax payments and employment growth}

Moving to growth rates, unconditionally on the sign or magnitude of employment or tax payment adjustments, a monthly drop of tax payments ratio by one percent leads to a 0.002 percent drop in the employment ratio, before the lockdown (March) and the midst of it (April), as reported in Table 2, column 4. This means that if payments growth declines by one percentage point during the first month of the lockdown, employment growth goes down by 0.002 percentage points during the same month. This claim holds for the before-and-after regression, controlling for industry fixed effects. Should we allow for firm, rather than sector, fixed effects, given two time periods, the estimate barely changes (the first column of results in Table 2). As many firms do not alter employment, focusing on either fired or hired labor, the result strengthens fourfold and becomes 0.009 .

This result can become non-trivial economically for the most affected companies. Within our sample, for instance, $50 \%$ or a larger reduction in tax payments were registered for more than 17,930 firms (or almost $50 \%$ with positive tax entries in April 2020), whereas $95 \%$ or a larger drop for more than 3290 firms (or more than 9\% with positive tax entries in April 2020). For instance, if companies paid $5 \%$ or fewer taxes compared to March, the effect on monthly employment growth was almost $0.03 \%$ point per month for those firms that experienced non-zero employment adjustment (the impact in ratio dropping to 0.05 leads to $\ln (0.05) \approx-3$, whereas the elasticity of the tax ratio on employment ratio is close to 0.01 ). The effect becomes substantially larger when firms report barely any activity, with the payments staying positive but approaching zero (e.g., using the conditional estimate of non-zero employment change, a $99.9 \%$ decrease in payments results in 6.9 times the parameter of 0.01 , or $0.069 \%$ point drop in employment monthly growth, turning to negative growth over a few months). ${ }^{9}$

Among the limitations of the model in (4.1) are the homogeneity of response parameters and an inability to learn the role of firm pre-shock conditions once controlled for the sector or section fixed effects. Though unreported, if tax payments are in fact allowed to be sector-specific, the parameters are found to be quite heterogeneous: the largest impact is registered for the hospitality and catering sector ( 0.016 on top of the baseline, i.e., 0.003, for agriculture) and the smallest for public administration and human health sectors (both turning negative) once firm fixed effects are controlled for (to be compared with the first column of Table 2). This result is quite intuitive-given the closure of hotels, restaurants, and borders, the hospitality sector suffered substantially. In contrast, public and health sectors primarily absorbed the health shock, possibly requiring more rather than less staff. What is more, the government has increased spending on the health sector, particularly by paying bonuses for those medics whose risk at work is highest.

\section{Firm pre-existing conditions}

As seen before, section fixed effects deliver almost identical pooled response parameters of tax payments on employment, as in the case with firm fixed effects. We thus delve into firm-specific effects that existed before the pandemic to explore if responses vary with financial conditions, turnover, and labor costs in 2019. We evaluate the following model:

$$
\begin{aligned}
& \triangle \text { ln Employment }_{i j}= \alpha_{j}+\beta_{1} \triangle \ln \text { Tax Payments }_{i j} \\
&+\beta_{2 j} \ln \text { Wedge }_{i j, 2019} \\
&+\beta_{3 j} \ln \text { Annual Turnover } \\
& i j, 2019 \\
&+\beta_{4 j} \ln \text { Total Labor Costs } \\
& i j, 2019+\varepsilon_{i j},
\end{aligned}
$$

where $\alpha_{j}$ is the sector fixed effect and Wedge ${ }_{i j, 2019} \equiv$ ln Annual Tax Liabilities - $\ln$ Annual Tax Payments denotes a wedge between accrued tax liabilities, as

\footnotetext{
${ }^{9}$ Since we only observe matched employment for March and April, we cannot compare inferred effects to the long-term trend monthly growth; however, the sample evidence tells that the average change in log employment (growth rate) is -0.008 across all firms.
} 
reported by the State Tax Agency, and factually paid taxes. A large positive value indicates large uncovered liabilities to the Tax Agency in the previous year. A negative value indicates an overpayment to the Tax Agency. The case of an annual surplus can be attributed to coverage of previous debts, intertemporal mismatches in sold goods and services, the low price of money, among others. Given that the annual wedge is predetermined, it can act as a state variable under lockdown circumstances that makes employment adjustment more likely (thus, a larger positive value should be associated with a larger yet negative employment adjustment) if financial frictions, as captured by indebtedness to the Tax Agency, matter for the employment reaction during the early phase of a pandemic. A positive sign or zero effect, on the other hand, indicates the irrelevance of prior financial frictions for employment change during the early stages of a pandemic, undoing some of the adjustment as captured by a homogeneous parameter on tax payments. We measure log of wedge by first taking logs of annual liabilities and tax payments, since the difference can be both negative and positive.

\subsection{Effects of tax wedges}

Table 3 reports results where a shock, as captured by a change in (log) tax payments, is complemented with the sector-specific tax wedge parameter along with sector fixed effects, sector-specific annual turnover (in 2019), and sector-specific total wage bill (labor payments) in 2019, all measured on the log scale. The importance of financial frictions and pre-existing debts cannot be overstated, as demonstrated in the literature on past crises. For instance, as documented by Chodorow-Reich (2013), the quality of a lender has an economically and statistically significant effect on employment at small and medium firms. Making use of evidence from the global financial crisis, the author finds that lack of credit caused firms to purge excess labor more than they otherwise would. Melcangi (2019) analyzes UK firm-level data and finds that cash-rich firms decreased their workforces for the period 2004-2013. Precautionary cash holdings increase among unconstrained firms in the face of a credit supply shock. Similarly, Benmelech et al. (2019) document a large and negative impact of financing frictions on firm employment during the Great Depression. The authors find that lack of access to credit leads to 10 to $33 \%$ of the aggregate decline in employment of large firms between 1928 and 1933. Mohamed and Sales (2015) document that credit market frictions may be the source of lower posting vacancies and higher unemployment level.

We control for the financial friction in 2019 by the tax wedge variable as well as for the size of the company and labor costs, also pre-determined from the health shock perspective. Using administrative data from the earliest periods of the imposed lockdown, we derive the following messages, summarized in Finding 1:

Finding 1 First, small companies respond most strongly to tax payment changes, whereas large (more than 50 employees) companies' employment response is only about $64 \%$ of the average and $53 \%$ of the reaction characterizing small (less than 20 employees) firms (see the first part of Table 2). Allowing for a rich control set (pre-shock heterogeneous financial frictions, heterogeneous effects of annual turnover, and total labor costs), a tax payment-induced change in employment is documented for small firms only.

Second, employment reactions are robust to different fixed effects (Table 2), conditioning on a rich control set (Table 3). ${ }^{10}$

Third, pre-shock financial frictions vary considerably, depending on the sector and firm size (turnover and employment). The largest negative effect (thereby aggravating employment adjustment due to preexisting financial frictions in 2019) is found for the most capital intensive sectors, namely manufacturing and real estate. ${ }^{11}$

Fourth, an interaction term, capturing a joint effect of tax payments and tax wedge on employment, turned out to be positive (thus financial frictions induce a larger change in employment) for the manufacturing sector, across all firm sizes, indicated that financial stability concerns should focus on manufacturing.

Starting from the first part of Table 3, we see that the larger a wedge is in 2019 , the more negative the change in employment growth for the agriculture sector. An increase in the tax wedge indicates that a

\footnotetext{
${ }^{10}$ If anything, the response gets slightly larger on average as well as for small firms (which dominate in the economy).

${ }^{11}$ The agriculture and construction sectors have slightly expanded employment, as covered in the Introduction, and are therefore omitted.
} 


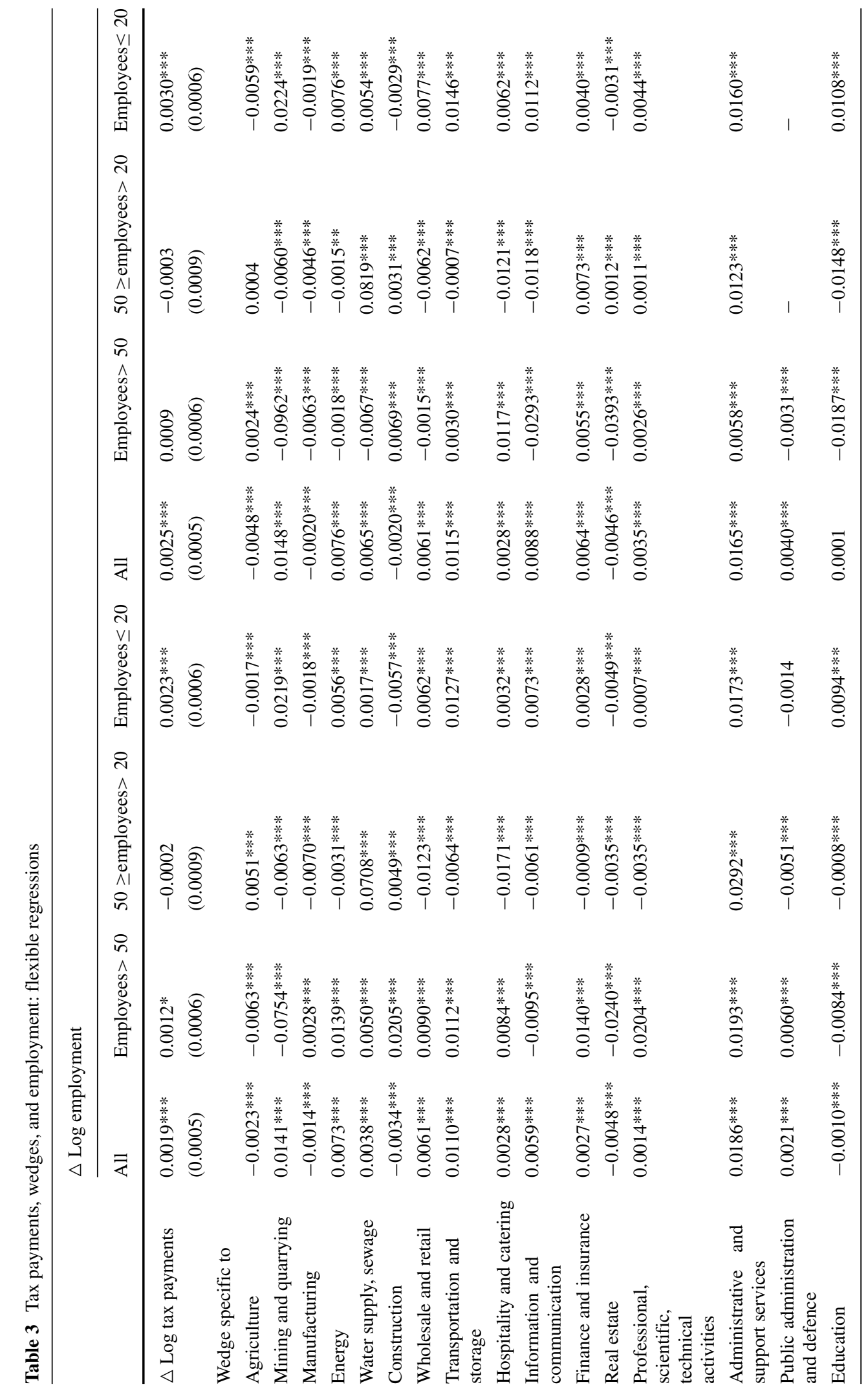




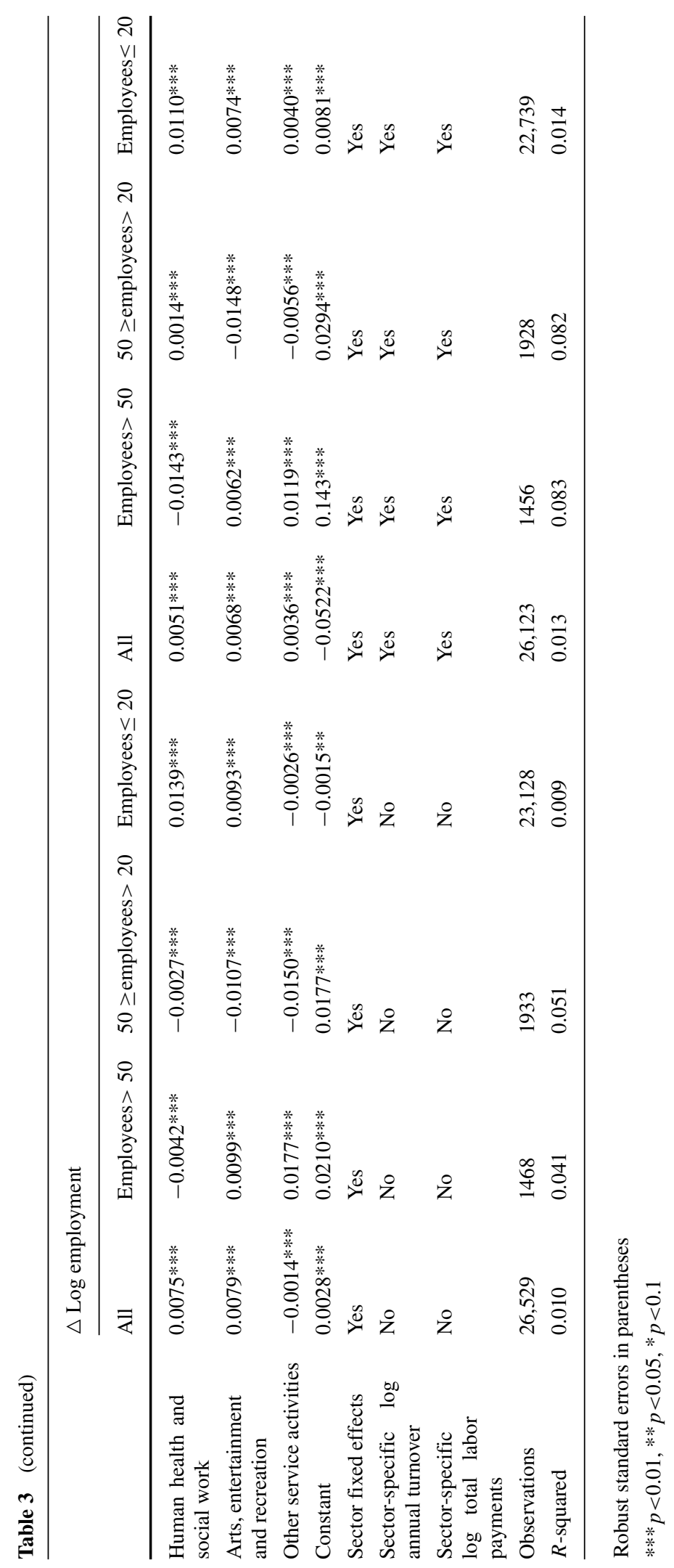


company has brought higher tax liability, which was not covered in 2019. Therefore, a negative parameter suggests that the change in employment, a dependent variable, is more negative, in addition to all other included variables. In other words, conditional on sector fixed effects and changes in VAT tax payments, sector-specific pre-conditions play an independent role in explaining a magnitude of employment adjustment. Interestingly, all sectors with a negative wedge effect in regression with many controls are featured in simpler regressions, too (compare the second and the first parts of Table 3). Yet, some wedges cease having a negative effect once sector-specific annual turnover and labor costs are included (in particular, education and other service activities). This finding illustrates that wedges are associated with size measures in specific sectors. Moreover, if richer section, rather than sector, fixed effects are used, then the qualitative results remain intact. The tax change responsiveness remains largely the same whereas a negative effect of tax wedge remains for the same sectors, with the inclusion of the education sector (five altogether). This finding illustrates that the preshock leverage matters for specific sectors, contrary to claims of this crisis having little or no similarities to previous disasters, despite healthier corporate balance sheets compared to the onset of previous crises (Reinhart, 2020). Admittedly, nature, the policy response, and global coverage are quite unique; nevertheless, economic forces are comparable to previous instances, as shown in Caballero and Simsek (2020), where a real shock can quickly translate into a downward asset price spiral, exacerbating negative effects.

Ex post, the first claim in Finding 1 seems to have been validated by the fact that large companies have returned state aid earlier than required. ${ }^{12}$ The main sectors which ended up with more negative employment adjustment due to the pre-existing frictions are predominantly supply-constrained (Baqaee and Farhi, 2020), where reductions in employment are driven by lockdown and social distancing orders as well as capacity reductions to ensure safe production and consumption. This points to why easing lockdown is so effective in an economy where the dominant effect is supply-based, and thus the aggregate negative effect is

\footnotetext{
${ }^{12}$ Though the data coverage is March and April 2020, expost, according to the business media, many large companies announced returning state aid in July 2020, indicating that the shock was absorbed much more easily by larger firms.
}

quite limited (at least for the early stage of the crisis). Of course, sectoral heterogeneity and the importance of firm size are not unique to this health crisis.

Our findings can be connected to the recent literature. For instance, Lin (2016) investigates the links between the rise of finance and firm employment dynamics during the 1982-2005 period in the USA. The author shows that a larger role of debt leads to workforce reduction, where most at risk are production and service workers compared to managers and professionals. This argument is supported by Cornille et al. (2019), who use matched bank-firm data during the European sovereign debt crisis. The authors find that credit constraints have led to employment reduction as well as an increase in the use of temporary layoff allowances among small and medium companies experiencing a negative demand shock. The main message holds outside the USA or Europe: Mizobata (2015) finds that Japanese industrial companies reduce hiring by $0.6 \%$ points in response to one standard deviation shock in the debt ratio. Using a historical perspective, a significant effect of disrupted credit supply on employment contraction is documented for the Great Depression period in Benmelech et al. (2019). By inhibiting firms' ability to substitute public debt for private debt, financial constraints necessitated large firms' employment adjustment, leading to a substantial decline in aggregate employment.

Although we do not observe different employment types or FTE shares, we can nevertheless infer what makes companies engage in more extensive adjustments than their counterparts. We capture size differences by conditioning on employment bins (less than 20 employees, between 20 and 50, and more than 50 employees). Moreover, we explore sector-specific responses to aggregate turnover and total labor costs in 2019 (pre-determined from the perspective of the shock). The effect of financial friction has been confirmed to depend heavily on firm size. For instance, a small agricultural firm reduces employment by more if it carries a financial obligation from 2019 while larger agricultural firms are capable of protecting their labor force (see both parts of the Table 3, a row of agriculture; the same result holds for construction companies). The importance of firm size and the effect of financial frictions has also been documented in the literature. For instance, relationship lending is crucial for small and medium firms (Berger and Udell, 
1995), which are between 40 and 65\% more likely to reduce their workforce if credit-constrained than their counterparts not facing such constraints (Cornille et al., 2019). In particular, credit constraints had powerful adverse effects on employment in the face of a negative demand shock, which also proxies well a current situation and agrees with the pandemic-induced immediate change at Lithuanian companies.

\subsection{Effects of interaction between tax wedges and tax payments}

Despite evidence of the tax wedge on change of employment during the first stage of the national lockdown, one could argue that employment changed for other reasons, beyond the ensuing pandemic. We thus enrich the model (5.1) with the interaction term, capturing changes in the payments parameter on employment change, depending on the tax wedge that was carried from 2019. The updated model reads as follows:

$$
\begin{aligned}
& \triangle \text { ln Employment }_{i j}= \alpha_{j}+\beta_{1} \triangle \ln \text { Tax Payments }_{i j} \\
&+\beta_{2 j} \triangle \ln \text { Tax Payments }_{i j} \\
& \times \ln \text { Wedge }_{i j, 2019} \\
&+\beta_{3 j} \ln \text { Wedge }_{i j, 2019} \\
&+\beta_{4 j} \ln \text { Annual Turnover } \\
& i j, 2019 \\
&+\beta_{5 j} \ln \text { Total Labor Costs } \\
& i j, 2019+\varepsilon_{i j} .(5.2)
\end{aligned}
$$

Therefore, a change in employment is driven not only by firm-specific changes in tax payments but also an interacted effect. In other words, the sensitivity is a function of predetermined financial frictions: $\beta_{1}+$ $\beta_{2 j} \ln \mathrm{Wedge}_{i j, 2019}$. If a sector-specific $\beta_{2 j}$ is positive, then the reaction is amplified due to the tax wedge; otherwise, it is attenuated. This interpretation is quite intuitive: a homogeneous reaction to VAT tax changes conceals a great deal of heterogeneity, and the augmented model (5.2) introduces financial frictions to partly account for that variation.

Table 4 collects updated evidence. Due to space constraints, we do not report wedges, as before, but only the interaction terms. The relevant comparison is, therefore, with the parameter on tax payment changes and the interaction term. We also report results with and without a rich control set for completeness, as in Table 3. Among the sectors whose employment responded more strongly to tax payments due to the pre-existing tax wedge are mining and quarrying, manufacturing, energy, education, health, and services. There are a few changes in signs, depending on the control variables and the firm size brackets, which indicate varying sensitivity to payment changes and employment variation. Only manufacturing firms had larger employment adjustments across the board if they inherited larger tax debts (across all size bins and control variables). This result points to the specifics about manufacturing, such as capital intensity, international trade, access to credit, playing an important role in pinning down employment adjustment and pre-existing financial frictions. As is clear from Table 4, there are more sectors among small businesses where financial frictions make employment adjustment larger. However, before drawing final conclusions, we explore the relationship between sales (paid taxes) and employment in more detail. Despite high data frequency and a focus on the initial lockdown period (March and April 2020), the relationship may still be determined beyond health shock reasons. We address that concern by resorting to an instrumental variable approach.

\section{Robustness and extensions}

To ensure that our results are causal, we also extend our framework to cover an instrumental variable approach. We merge COVID-19 testing data at the sectoral level with the matched firm taxes and employment dataset. The causal inference not only helps us learn about firm adjustments but also enables us to draw robust policy implications. The fact that capitalintensive sectors adjusted employment more strongly due to existing financial frictions, among other things, may also indicate a lack of targeted policies that take sectoral and firm-size differences seriously into account. Moreover, small businesses reduced employment more strongly if they inherited larger liabilities from the previous year, even in the very first months of the lockdown.

\subsection{Baseline panel IV regression}

The panel IV regression exploits variation in COVID19 tests across economic activities. Having data on positive tests using the same classification as the firm data, we can construct a fitted value of a change in tax payments that results from exposure to the 


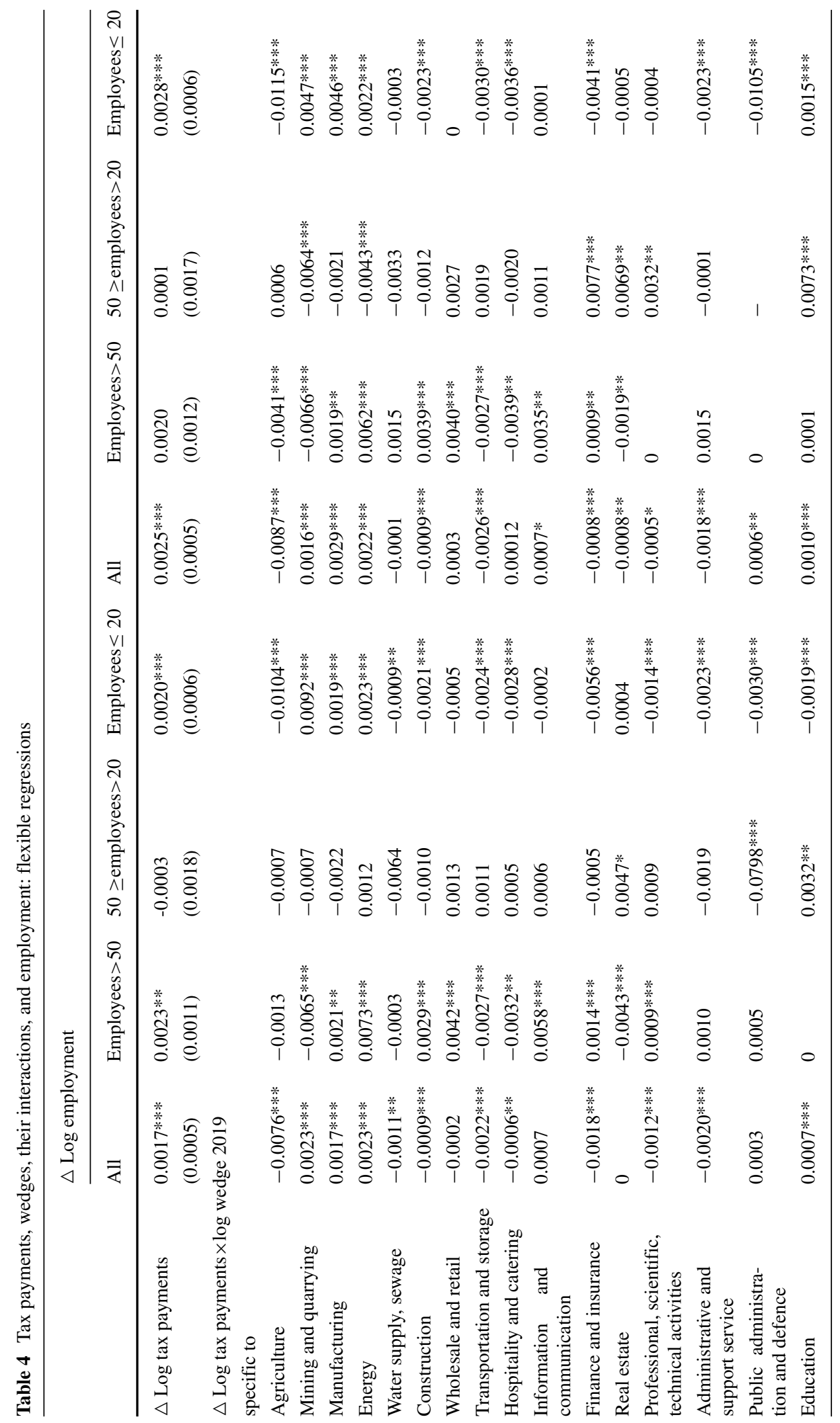




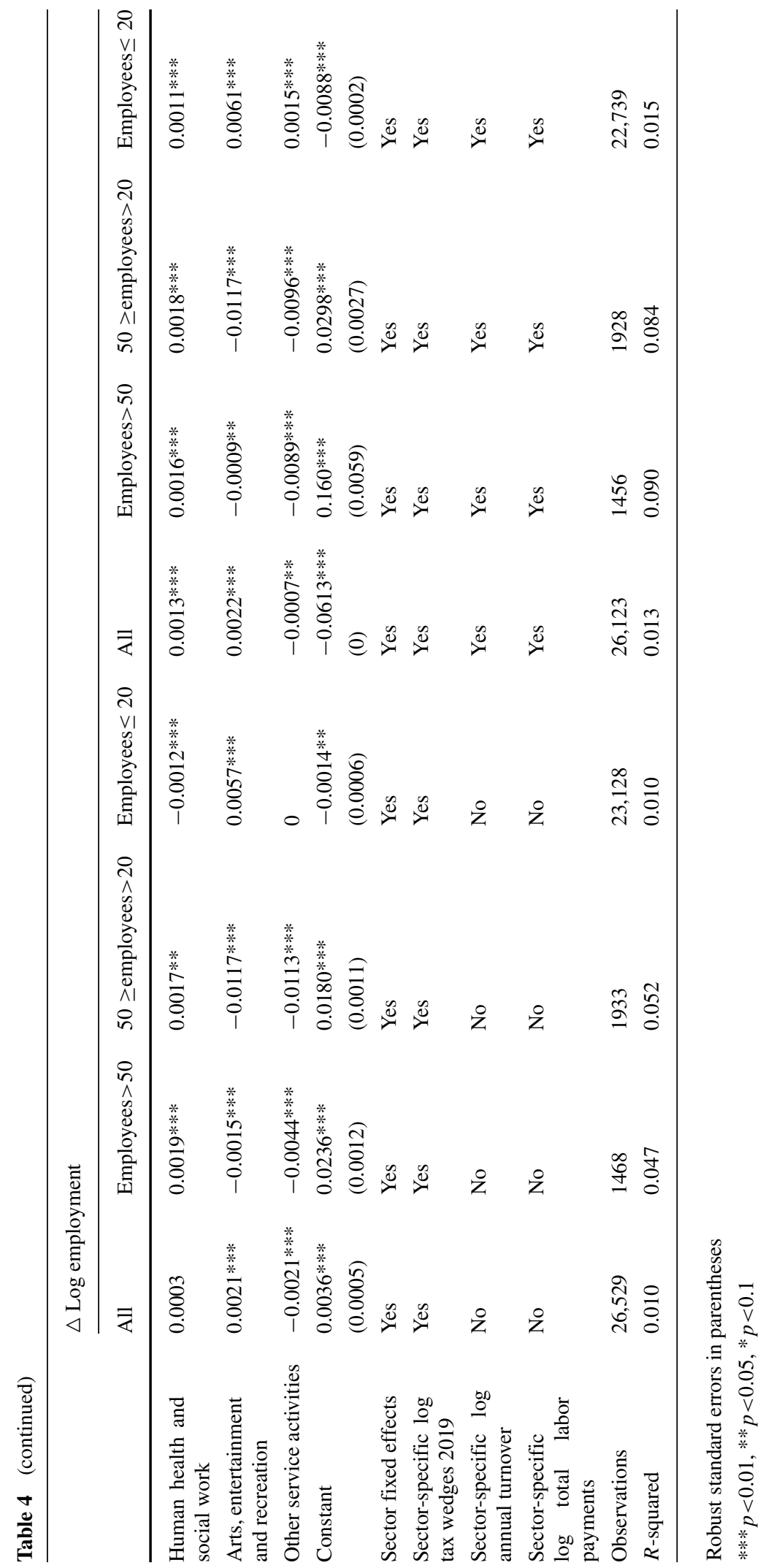


virus. Hence, previously mentioned concerns about the strategic action to reduce payments are substantially alleviated. The virus spread is exogenous from the financial and employment decisions. This strategy is like running a difference-in-differences with a continuous measure of exposure. We find that indeed a change in value-added tax payments is substantially reduced with an increase in positive COVID-19 tests, passing the standard IV relevance test (since we only have one IV, we cannot conduct the overidentification test). Applying this strategy, we are led to the updated Finding 2:

Finding 2 First, the fixed-effects instrumental variable panel model delivers around three times larger effect of payment changes on employment. This result indicates that the omitted variable problem may have indeed attenuated the true effect, particularly among large enterprises, for which sensitivity from payments to employment increases ten times.

Second, the interaction term between tax payments and tax wedge amplifies employment adjustment in mining, manufacturing, energy, water supply, real estate, arts, and service sectors. Notably, these effects predominantly hold for small businesses, suggesting that small enterprises disproportionately respond to pre-existing financial and related conditions even at the earliest stages of the lockdown.

Third, there is a staggering heterogeneity of the payment effect on employment: the largest responsiveness is registered for the hospitality and catering sectors. Allowing for sectoral parameter heterogeneity, an interaction term between tax payments, instrumented by positive COVID-19 tests, and the tax wedge, as before, remains for manufacturing firms, independently of firm sizes. In other sectors, the wedge can increase or decrease responsiveness, depending on firm size.

We start with Table 5. There are two sets of regressions: (a) regression uses tax payments, instrumented by positive COVID-19 tests and controls for firm unobserved heterogeneity, and (b) regression, besides, accounts for the interaction term between payments and tax wedge. The first result is a double-sized parameter on payments, indicating that the adjustment is larger once endogeneity concerns are addressed. In other words, exploiting an exogenous variation in positive COVID-19 tests at the sectoral level enables us to extract drops in tax payments due to shock severity rather than other reasons. The second result is a further increase in the parameter once interaction terms are taken into consideration (regression b). Allowing for more flexibility, the average response gets stronger since some sectors have a negative effect, stemming from the interaction term. In other words, a change in payments has a wedge component, $\beta_{1}+$ $\beta_{2 j}$ ln Wedge ${ }_{i j, 2019}$. An increase in responsiveness due to the carried liabilities (higher wedge) from 2019 is registered for mining, manufacturing, energy, water supply, real estate, arts, and other services. Notably, the result holds for small firms only, suggesting that access to alternative adjustment margins even at the earliest stages of the lockdown were substantially more limited to small compared to medium and large businesses.

We excluded construction and public administration because, as covered in the Introduction, these sectors have slightly expanded rather than downsized. It could be that their wedges were lower than in other sectors to begin with, thereby enabling them to slightly expand even if sales (and taxes) have diminished. Equally, some firms in those sectors could have experienced an increase in sales, e.g., implementing construction works that have been long overdue and expanding the public sector to counteract a negative shock in other sectors. A few sectors have negative signs, meaning that higher liabilities from the past diminish responsiveness in terms of employment adjustment. Those sectors are hospitality and catering, finance, education (among small businesses). The latter two could pursue their activities through teleworking, whereas the hospitality sector is a puzzle. The expectation is that the adjustment should have been one of the largest, but the interaction term, instead, enters with a negative sign.

\subsection{Extended panel IV regression}

To explore this finding further, we amend the baseline firm fixed effects model (4.1) as follows:

$$
\begin{aligned}
& \ln _{\text {Employment }} \text { }_{i j, t}= \alpha_{i}+\beta_{1} \ln \text { Tax Payments }_{i j, t} \\
&+\beta_{1 j} \ln \operatorname{Tax} \text { Payments }_{i j, t} \\
&+\beta_{2 j} \ln \text { Tax Payments } \\
& i j, t \\
& \times \ln \text { Wedge }_{i j, 2019}+\varepsilon_{i j, t} .
\end{aligned}
$$


Table 5 Tax payments, wedges, and employment: IV regressions

\begin{tabular}{|c|c|c|c|c|}
\hline & \multicolumn{4}{|c|}{ Log employment } \\
\hline & All & Employees $>50$ & $50 \geq$ employees $>20$ & Employees $\leq 20$ \\
\hline \multirow[t]{2}{*}{ a) Log tax payments } & $0.0066^{* * *}$ & $0.0093 * * *$ & 0.0014 & $0.0059 * * *$ \\
\hline & $(0.0011)$ & $(0.0025)$ & $(0.0018)$ & $(0.0019)$ \\
\hline \multirow[t]{2}{*}{ b) Log tax payment } & $0.0088 * * *$ & $0.0272 *$ & -0.0036 & $0.0075^{* * *}$ \\
\hline & $(0.0018)$ & $(0.0151)$ & $(0.0076)$ & $(0.0019)$ \\
\hline \multicolumn{5}{|c|}{ b) Log tax payments $\times$ log wedge 2019 specific to } \\
\hline Agriculture & $0.0027 * *$ & $0.0428 * *$ & 0.0023 & -0.0010 \\
\hline Mining and quarrying & $0.0019 * * *$ & 0.0116 & -0.0022 & $0.0030 * * *$ \\
\hline Manufacturing & $0.0062 * * *$ & $0.0239 *$ & -0.0047 & $0.0058 * * *$ \\
\hline Energy & $0.0023^{* * *}$ & 0.0131 & -0.0013 & $0.0029 * * *$ \\
\hline Water supply, sewage & $0.0079 * * *$ & 0.0273 & -0.0143 & $0.0072 * * *$ \\
\hline Construction & $0.0014 * * *$ & $0.0138 * *$ & -0.0013 & $0.0011 * * *$ \\
\hline Wholesale and retail & $0.0036^{* * *}$ & $0.0299 *$ & -0.0091 & 0.0016 \\
\hline Transportation and storage & $0.0025^{* *}$ & 0.0112 & -0.0028 & 0.0011 \\
\hline Hospitality and catering & $-0.0095 * * *$ & 0.0228 & $-0.0065^{*}$ & $-0.0142 * * *$ \\
\hline Information and communication & $0.0058 * * *$ & $0.0411 * *$ & 0 & 0.0027 \\
\hline Finance and insurance & 0 & $0.0073^{*}$ & -0.0019 & $-0.0041 * * *$ \\
\hline Real estate & $0.0073^{* * *}$ & 0.0100 & -0.0072 & $0.0062 * * *$ \\
\hline Professional, scientific, technical activities & $0.0019 * *$ & $0.0064 *$ & -0.0040 & 0.0011 \\
\hline Administrative and support services & -0.0002 & 0.0195 & $-0.0178 * * *$ & $-0.0014^{*}$ \\
\hline Public administration and defence & $0.0032 * * *$ & $0.0087^{*}$ & -0.0019 & $0.0063 * * *$ \\
\hline Education & $0.0018 * * *$ & $0.0078 *$ & 0.0009 & $-0.0075^{* * *}$ \\
\hline Human health and social work & $0.0032 * * *$ & $0.0108 *$ & 0.0001 & 0.0008 \\
\hline Arts, entertainment and recreation & $0.0021 * *$ & 0.0070 & -0.0071 & $0.0022 * *$ \\
\hline Other service activities & $0.0040 * * *$ & 0.0059 & -0.0218 & $0.0056^{* * *}$ \\
\hline \multirow[t]{2}{*}{ a) Constant } & $1.588 * * *$ & $4.768 * * *$ & $3.414 * * *$ & $1.244 * * *$ \\
\hline & $(0.0069)$ & $(0.0240)$ & $(0.0153)$ & $(0.0119)$ \\
\hline \multirow[t]{2}{*}{ b) Constant } & $1.592 * * *$ & $4.746 * * *$ & $3.425 * * *$ & $1.270 * * *$ \\
\hline & $(0.0078)$ & $(0.0538)$ & $(0.0213)$ & $(0.0084)$ \\
\hline a) Observations & 52,240 & 2684 & 3917 & 45,860 \\
\hline b) Observations & 41,349 & 1929 & 2995 & 36,582 \\
\hline
\end{tabular}

Fixed effects IV regressions. Specification a) includes changes in VAT tax payments, instrumented by a share of positive COVID-19 tests at the industry level; b) includes an interaction between a change in VAT tax payments and tax wedge in 2019, instrumented by the positive COVID-19 tests at the industry level. Robust standard errors in parentheses.

$* * * p<0.01, * * p<0.05, * p<0.1$

We have thus allowed for the sector-specific effect $\beta_{1 j}$ and the sector-specific interaction term. The pooled parameter $\beta_{1}$ adjusts the sector-specific one, i.e., we need to add the two to learn the sector $j$ 's sensitivity to changes in tax payments. Table 6 collects evidence. Due to space constraints, we have merged sector-specific parameters into columns, instead of repeating the rows. First, the pooled parameter is negative but carries no meaning on its own. When added with the sector-specific estimates, the largest effect 


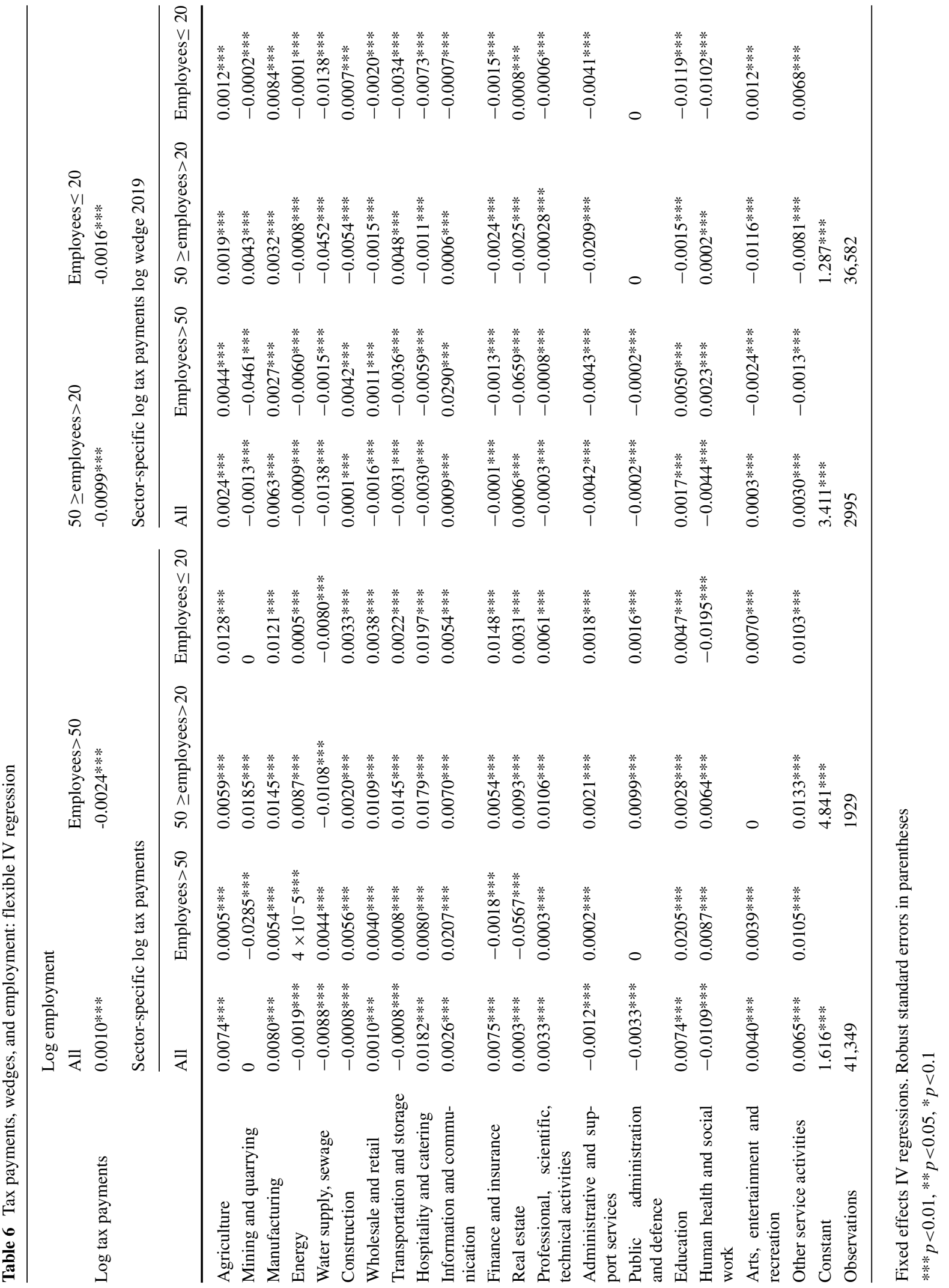


is confirmed for the hospitality and catering sector. Indeed, the parameter $0.0182+0.0009=0.0191$ is 2-3 times larger compared to the homogeneous IV baseline result (Table 5, regressions a) and b)). Hence, even if the interaction term is negative, the ultimate adjustment is substantial, helping to solve the previously encountered puzzle.

Among small businesses, manufacturing, real estate, arts and entertainment, and other service firms had positive sector-specific reactions to the VAT payment change along with the amplifying effect from the tax wedge inherited from 2019. As before, we have excluded agriculture and construction as those sectors have slightly expanded, so it could be that they received more rather than fewer orders. Among those sectors that reacted positively to the payment changes, the interaction term was negative: wholesale and retail, hospitality, finance and insurance, and professional activities (among all firms). All but hospitality sectors were able to function, so there could be a few scenarios. One, their VAT payments have increased, but employment did not due to uncertainty, and the negative interaction term partly captures that. Two, though the VAT payments dropped, the employment remained stable, and the interaction term thereby captures the attenuation effect. The hospitality sector, as explained, had the largest sector-specific reaction to VAT tax changes; however, the attenuation term could provide an early indication about the wait-and-see strategy despite the existing financial obligation from the previous year. One of the risks of saving nonviable businesses is the emergence of a zombie economy, and this early finding may point to that phenomenon. However, the jury is still out as it is much too early to draw definite conclusions about the viability of indebted or otherwise financially fragile firms.

Though we can robustly identify employment changes across sectors and firm-size bins, allowing for financial frictions, we document merely the firstround effect. In addition to the immediate shock, some higher-order effects would likely kick in. Among them, there are sectoral spillovers and global value chain changes, particularly for the globally integrated sectors. Indeed, Merlevede and Michel (2020) find that offshoring leads not only to the import of intermediates that were produced in-house but also a drop in domestically sourced inputs, thereby leading to an amplified negative demand shock in the domestic economy. The authors label this channel as a "downstream offshoring" shock and document a robust negative effect on employment using Belgium firm-level data. Given that the Lithuanian economy is small and very open, there will undoubtedly be higherorder effects, which remain to be evaluated once the situation becomes clearer and more data becomes available. What has helped for the first stage of the crisis was predominantly supply-driven constraints, which, after having been relaxed, enabled the economy to quickly adapt (at least compared to its Western counterparts). Worrisome, however, is the uncertainty surrounding the length of the crisis, the effectiveness of the vaccines, virus mutations, unequal impacts across trade partners, and scarring effects of layoffs, particularly for small businesses that suffer more due to the pre-existing financial frictions.

\section{Conclusions}

Using administrative firm-level data, our research demonstrates that what makes the COVID-19-induced crisis different is unequal sectoral exposure to the spread of the virus and different levels of preparedness to adjust workplace conditions to mitigate workers' contagion risk. We find very moderate employment adjustments in response the first national lockdown in March 2020. What seems to have helped the Lithuanian economy was the dominance of supply-driven forces. This helps to explain why upon lifting lockdown restrictions, the economy has bounced back so quickly, and the constrained firms got back on track. However, uncertainty about external demand, the length of the pandemic, and the stringency of further nationwide lockdowns all make it very hard to predict the future. It is more worrying that demand shocks are starting to play out-for instance, residents and corporate (enterprise) deposits have increased substantially (e.g., corporate deposit growth was six times larger than the average growth over the corresponding period) from the beginning of the pandemic in March and throughout the year 2020. These developments indicate that increasing precautionary sav- 
ings and deferred investment may negatively affect the medium run should the health solution take more time than expected.

However, what is particularly problematic is the disproportionate effect of financial frictions and preexisting conditions among small businesses. They tended to reduce employment more strongly than their counterparts across sectors. We also find that the largest sectoral reaction is registered for the hospitality and catering sector. Allowing for sectoral parameter heterogeneity, an interaction term between tax payments, instrumented by positive COVID-19 tests, and the tax wedge, remains for manufacturing firms, independently of their sizes, and statistical models used. Among small firms, manufacturing, real estate, arts and entertainment, and other service firms had positive sector-specific reactions to the VAT payment change along with an amplifying effect from the tax wedge. This means that a greater number of capital-intensive and service sector firms downsized more if they had higher tax liabilities before the pandemic in 2019 . These are early effects from the first months of the lockdown in 2020. On the one hand, we can identify business reactions, unaffected by policy interventions. On the other hand, employment is a costly adjustment margin and takes time to transpire.

Our results should be thus interpreted as a very early signal about firms' immediate reaction. We lack evidence about the intersectoral movements of people, within-firm reallocations, and full effects of furlough schemes, as well as sectoral and global value chain adjustments. ${ }^{13}$ Even with the evidence at hand, a few policy implications are clear. The fact that small firms and specific sectors (e.g., capital-intensive ones and

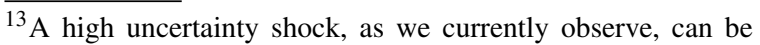
thought of as an aggregate demand shock (Leduc and Liu, 2016). We can, therefore, draw important lessons from Uysal et al. (2015). They analyze trade-induced layoffs by US firms to study the interaction between firm productivity and trade liberalization as key determinants of firm-level job destruction due to trade. The authors find that the number of trade-induced layoffs increases with firm productivity for non-exporting firms but decreases with firm productivity for exporting firms. These findings suggest that even exporting firms may lay off some workers who specialized in domestic sales, as well as engage in the within-firm reallocation of workers. What matters is not only sectoral heterogeneity, which we address, but also varying openness degrees and firms' productivities, which possibly get affected by such a large shock if their technology can no longer be used in the new normal. All these effects remain to be fully worked out with time and more data.
}

services) have experienced larger employment reductions due to pre-existing financial frictions indicates a lack of targeted policies, especially when it comes to liquidity needs. Though absent during the analyzed period, the central banks' policies may amplify existing heterogeneity if they extend credit for medium and large companies, thereby not reaching small businesses through financing and refinancing schemes. Our results also confirm an early warning due to Baqaee and Farhi (2020) that, though the demand stimulus is needed, if untargeted, it gets dissipated in price increases due to unequal demand constraints across sectors. It remains to work out a full transition path into the new normal; what is already clear, however, is that policymaking should have taken into account, in particular, sectoral differences (and thus the nature of a shock) and small firms' pre-crisis leverage, which, if continues to be unaddressed, may lead to overly large social and human capital costs.

Acknowledgements I thank the Editor, Roy Thurik, and two anonymous referees for helpful and constructive comments as well as Yifei Zhang for advice during the remote workshp.

Funding Support from Iceland, Liechtenstein and Norway through the EEA grants (project no. S-BMT-21-8 (LT08-2LMT-K-01-073)) under a grant agreement with the Research Council of Lithuania (LMTLT) is gratefully acknowedged.

\section{Declarations}

Disclaimer The views expressed in this paper are those of the author and do not necessarily reflect the position of the Bank of Lithuania or the Eurosystem.

\section{References}

Auray, S., \& Eyquem, A. (2020). The macroeconomic effects of lockdown Policies. Documents de Travail de l'OFCE 202010, Observatoire Francais des Conjonctures Economiques (OFCE). https://ideas.repec.org/p/fce/doctra/2010.html.

Baqaee, D., \& Farhi, E. (2020). Supply and demand in disaggregated Keynesian economies with an application to the Covid-19 Crisis. Working Paper 27152, National Bureau of Economic Research https://doi.org/10.3386/w27152. http:// www.nber.org/papers/w27152.

Bekaert, G., Engstrom, E., Ermolov, A. (2020). Aggregate demand and aggregate supply effects of COVID-19: A realtime analysis. Finance and Economics Discussion Series 2020-049, Board of Governors of the Federal Reserve System (U.S.) https://doi.org/10.17016/FEDS.2020.049. https://ideas.repec.org/p/fip/fedgfe/2020-49.html. 
Benmelech, E., Frydman, C., Papanikolaou, D. (2019). Financial frictions and employment during the Great Depression. Journal of Financial Economics, 133(3), 541-563. https://doi.org/10.1016/j.jfineco.2019.02. https:// ideas.repec.org/a/eee/jfinec/v133y2019i3p541-563.html.

Berger, A.N., \& Udell, G.F. (1995). Relationship lending and lines of credit in small firm finance. The Journal of Business, 68(3), 351-381. http://www.jstor.org/stable/2353332.

Berton, F., Mocetti, S., Presbitero, A.F., Richiardi, M. (2018). Banks, firms, and jobs. The Review of Financial Studies, 31(6), 2113-2156. https://doi.org/10.1093/rfs/hhy003. https://academic.oup.com/rfs/article-pdf/31/6/2113/ 24833096/hhy003.pdf.

Boeri, T., Garibaldi, P., Moen, E.R. (2018). Financial constraints in search equilibrium: Mortensen Pissarides meet Holmstrom and Tirole. Labour Economics, 50, 144-155. https://doi.org/10.1016/j.labeco.2017.06.003. http://www.sciencedirect.com/science/article/pii/ S092753711730266X.

Caballero, R.J., \& Simsek, A. (2020). A model of asset price spirals and aggregate demand amplification of a "Covid19" shock. Working Paper 27044, National Bureau of Economic Research . http://www.nber.org/papers/w27044.

Chodorow-Reich, G. (2013). The employment effects of credit market disruptions: firm-level evidence from the 20089 financial crisis. The Quarterly Journal of Economics, 129(1), 1-59. https://doi.org/10.1093/qje/qjt031. https:// academic.oup.com/qje/article-pdf/129/1/1/30626547/ qj031.pdf.

Cornille, D., Rycx, F., Tojerow, I. (2019). Heterogeneous effects of credit constraints on SMEs' employment: Evidence from the European sovereign debt crisis. Journal of Financial Stability, 41(C), 1-13. https://doi.org/10.1016/j.jfs.2019.02.001. https://ideas. repec.org/a/eee/finsta/v41y2019icp1-13.html.

Domenech, J. (2008). Labour market adjustment a hundred years ago: the case of the Catalan textile industry, 1880-1913. Economic History Review, 61(1), 1-25. https://doi.org/10.1111/j.1468-0289.2007.. https://ideas. repec.org/a/bla/ehsrev/v61y2008i1p1-25.html.

Elsby, M.WL., \& Michaels, R. (2013). Marginal jobs, heterogeneous firms, and unemployment flows. American Economic Journal: Macroeconomics, 5(1), 1-48. https://doi.org/10.1257/mac.5.1.1. https://www.aeaweb. org/articles?id=10.1257/mac.5.1.1.

Gali, J., Smets, F., Wouters, R. (2012). Unemployment in an estimated new Keynesian model. NBER Macroeconomics Annual, 26(1), 329-360. https://doi.org/10.1086/663994. https://ideas.repec.org/a/ucp/macann/doi10.1086-663994. html.

Goecke, M. (2013). Layoffs in a recession and temporary employment subsidies when a recovery is expected. Review of Economics, 64(1), 73-84. https://ideas.repec.org/a/lus/ reveco/v64y2013i1p73-84.html.

Hall, R.E., \& Lazear, E.P. (1984). The excess sensitivity of layoffs and quits to demand. Journal of Labor Economics, 2(2), 233-257. https://doi.org/10.1086/298032. https:// ideas.repec.org/a/ucp/jlabec/v2y1984i2p233-57.html.

Huynh, K.P., Ostrovsky, Y., Petrunia, R.J., Voia, M.C. (2017). Industry shutdown rates and permanent layoffs: evidence from firm-worker matched data. IZA Journal of Labor Economics, 6(1), 1-31. https://doi.org/10.1186/s40172-017-0057-0. https://ideas.repec.org/a/spr/izalbr/v6y2017i1d10. 1186_s40172-017-0057-0.html.

Kwapil, C. (2009). Actual implications of the current economic crisis for austrian enterprises - results of a company survey. Monetary Policy \& the Economy (4):98-110. https://ideas. repec.org/a/onb/oenbmp/y2009i4b5.html.

Lastauskas, P., \& Stakenas, J. (2018). Openness and structural labor market reforms: ex ante counterfactuals. Contemporary Economic Policy, 36(4), 723-757. . https://ideas.repec. org/a/bla/coecpo/v36y2018i4p723-757.html.

Leduc, S., \& Liu, Z. (2016). Uncertainty shocks are aggregate demand shocks. Journal of Monetary Economics, 82(C), 20-35. https://doi.org/10.1016/j.jmoneco.2016.07. https:// ideas.repec.org/a/eee/moneco/v82y2016icp20-35.html.

Lin, K.H. (2016). The rise of finance and firm employment dynamics. Organization Science, 27(4), 972-988. https://doi.org/10.1287/orsc.2016.1073. https://ideas.repec. org/a/inm/ororsc/v27y2016i4p972-988.html.

Lydon, R., Matha, T.Y., Millard, S. (2019). Short-time work in the Great Recession: firm-level evidence from 20 EU countries. IZA Journal of Labor Policy, 8(1), 1-29. https://doi.org/10.1186/s40173-019-0107-2. https://ideas.repec.org/a/spr/izalpo/v8y2019i1d10. 1186_s40173-019-0107-2.html.

Melcangi, D. (2019). Firms' precautionary savings and employment during a credit crisis. Staff Reports 904, Federal Reserve Bank of New York. https://ideas.repec.org/p/ fip/fednsr/904.html.

Merlevede, B., \& Michel, B. (2020). Downstream offshoring and firm-level employment. Canadian Journal of Economics, 53(1), 249-283. https://doi.org/10. 1111/caje.12425. https://ideas.repec.org/a/wly/canjec/ v53y2020i1p249-283.html.

Mihailov, A. (2020). Quantifying the macroeconomic effects of the COVID-19 lockdown: Comparative simulations of the estimated Galí-Smets-Wouters model economics \& management discussion papers em-dp2020-07, Henley Business School, Reading University. https://ideas.repec.org/p/ rdg/emxxdp/em-dp2020-07.html.

Mizobata, H. (2015). Hiring, investments, and financial distress: evidence from a Panel VAR analysis of Japanese firms. Economics Bulletin, 35(4), 2558-2566. https://ideas. repec.org/a/ebl/ecbull/eb-15-00532.html.

Mohamed, I.B., \& Sales, M. (2015). Credit imperfections, labor market frictions and unemployment: a DSGE approach. Universite Paris1 Pantheon-Sorbonne (Post-Print and Working Papers) hal-01082491, HAL. https://ideas. repec.org/p/hal/cesptp/hal-01082491.html.

Qi, S., \& Schlagenhauf, D.E. (2018). On corporate income taxes, employment, and wages. Economic Synopses (7):13. https://doi.org/10.20955/es.2018.7, https://ideas.repec. org/a/fip/fedles/00103.html.

Reinhart, C.M. (2020). This time truly is different. https://www.project-syndicate.org/commentary/covid19-crisis$\mathrm{h}$ as-no-economic-precedent-by-carmen-reinhart-2020-03? barrier=accesspaylog.

del, R.io.-C.hanona.R.M., Mealy, P., Pichler, A., Lafond, F., Farmer, J.D. (2020). Supply and demand shocks 
in the COVID-19 pandemic: an industry and occupation perspective. Oxford Review of Economic Policy, 36(Supplemen), 94-137. https://ideas.repec.org/a/oup/ oxford/v36yisupplement_1ps94-s137..html.

Uysal, P., Yotov, Y.V., Zylkin, T. (2015). Firm heterogeneity and trade-induced layoffs: An empirical investigation. European Economic Review, 75(C), 8097. https://doi.org/10.1016/j.euroecorev.2015. https://ideas. repec.org/a/eee/eecrev/v75y2015icp80-97.html.

Publisher's note Springer Nature remains neutral with regard to jurisdictional claims in published maps and institutional affiliations. 